\title{
O ALÉM-DO-HOMEM COMO TAREFA FILOSÓFICA ${ }^{1}$
}

Jelson Oliveira ${ }^{2}$ (PUC-PR)

jelson.oliveira2012@gmail.com

Resumo: Pretende-se, nesse artigo, analisar o conceito de além-do-homem em Nietzsche a partir da ideia de Züchtung, compreendendo-se esta como uma tarefa assumida pela própria filosofia nietzschiana e legada como missão para toda a filosofia. Nesse sentido, inicia-se com uma análise do conceito de Züchtungna obra de Nietzsche, articulando-a às condições próprias para o cultivo e a criação do Übermensch e à efetivação da sua doutrina. A partir daí, avaliar-se-á como a criação de tais condições exige a superação do desgosto para garantir a possibilidade da criação do além-do-homem.

Palavras-chave: Züchtung; além-do-homem; Übermensch; tarefa filosófica; doutrina.

\section{INTRODUÇÃO}

Ao longo da sua obra, Nietzsche refere-se insistentemente ao papel da cultura (e da moral) como um processo de aprimoramento, elevação e criação de homens superiores. Tal ideia é expressa por meio do conceito de Züchtung, um termo também utilizado no âmbito da biologia, como referência ao cultivo de espécies novas a partir de uma intencionalidade e da imposição de uma disciplina rigorosa. Ao aplicar tal perspectiva ao homem, o filósofo alemão se

\footnotetext{
${ }^{1}$ Recebido: 05-06-2020/ Aceito: 06-07-2020/ Publicado on-line: 05-10-2020.

${ }^{2}$ É professor do Programa de Pós-Graduação em Filosofia da Pontifícia Universidade Católica do Paraná, Curitiba, PR, Brasil.
} 
refere à ideia tanto de superação do homem quanto de sua elevação em direção ao além-do-homem, algo que seria assumido como uma nova tarefa filosófica, uma tarefa para o filósofo do futuro, portanto.

A temática da Züchtung, assim, liga-se diretamente à negação do acaso no aparecimento do além-do-homem: como Nietzsche sugere, se até agora homens superiores como Cesar Borgia (EH, Porque escrevo tão bons livros, 1), Shakespeare e Stendhal (KSA 10, 27[59]), foram frutos do acaso e, portanto, não passaram de expressões individuais e particulares que logo se perderam, este tipo poderia ser buscado, preparado e conquistado por uma elevação seletiva que fizesse da cultura um laboratório capaz de fortalecer as forças vitais daqueles que, superando o desgosto e o ressentimento diante da vida, fossem capazes de alcançar a força dos criadores e legisladores. Em um fragmento póstumo de 1884 (KSA 11,26[407]), Nietzsche trata exatamente desse problema: "O problema do cultivo, porque a vida do indivíduo é muito curta" [Das Problem der Züchtung, weileinEinzelnerzukurzlebt], fazendo referência à necessidade de superar o acaso em nome dos esforços de cultivo. Como problema, Züchtungdeve ser assumido como atribuição de uma filosofia verdadeira, aquela que assume a problematização e a criação dos valores como seu empreendimento central. Se até agora a verdade tinha sido compreendida como a tarefa primordial da filosofia, com Nietzsche ela dá lugar à pergunta sobre o valor, dado que toda verdade é, antes de qualquer coisa, uma projeção valorativa. 


\section{A TAREFA}

O conceito de Züchtung aparece nos fragmentos póstumos a partir de 1873, embora sua frequência seja notável a partir de 1883, precisamente o período de elaboração de Assim Falou Zaratustra, o que liga o conceito, como sugeriu Patrick Wotling no seu livro Oui, l'hommefut um essai: a philosophie de l'avenirselon Nietzsche (2016), diretamente à tarefa preparatória assumida pelo profeta do eterno retorno.

Em Além de bem e mal, por exemplo, principalmente no capítulo $\mathrm{O}$ que é nobre?, que, como se sabe, desenvolve e aprofunda ideias anteriores, já iniciadas em um texto de 1872, A disputa de Homero, o conceito de além-do-homem é apresentado diretamente ligado à tarefa de "tirania" da moral contra o laisseraller da natureza e uma educação do espírito pela vida da "disciplina e cultivo espiritual" [geistigenZuchtund Züchtung] (ABM, 188); ao ensino do futuro do homem e à preparação de "grandes empresas e tentativas globais de disciplinação e cultivo" [GesammtVersuche von Zuchtund Züchtung vorzubereiten] (ABM, 203); ao desafio do homem europeu e à sua crítica à democracia como perigo ao "cultivo de tiranos" [Züchtung von Tyrannen] (ABM 242); ao chamado "problema europeu" e ao "cultivo de uma nova casta que governe a Europa" [an die Züchtung einerneuenüber Europa regierendenKaste] (ABM, 252) e ao enfrentamento das "condições desfavoráveis" para o nascimento de uma "nova espécie", de um tipo "firme e forte" gerado por uma comunidade política, "para fins de cultivo" [Zweck der Züchtung na] (ABM, 262).

Emum fragmento póstumo de 1883 (KSA 13,15[4]), Nietzsche refere-se diretamente à tarefa de cultivar o além- 
do-homem a partir de uma ruptura com os ideais do passado e escolha de condições apropriadas: "Ou para o além-dohomem $^{3}$ (cultivo a partir da escolha do lugar, gênero, comida etc.)" [Oder zum Übermenschen (Züchtung durchWahl des Ortes Geschlechter Nahrungusw]. Trata-se de contruir as condições para o fortalecimento da vida, torna-la mais forte: "Desenvolver toda a cadeia da vida, de forma que ela se torne cada vez mais potente - eis a tarefa" (KSA 13, 11 [83]).

Em outro fragmento póstumo, Nietzsche será ainda mais preciso quanto à tarefa da filosofia, indicando o modo pelo qual ela poderia ser cumprida: "Tarefa: ver as coisas como elas são! Meio: poder vê-las com mil olhos, de muitas pessoas! Acentuar a importância do impessoal era um caminho enganoso (...) é preciso formar novos seres" (KSA 9, 11[65]). Nessa passagem Nietzsche não apenas apresenta a criação de novos seres como uma tarefa filosófica, como apresenta a necessidade de uma visão multifacetada que rompa, portanto, com a visão unilateral e limitada que orientou a busca pela verdade na tradição filosófica. Só assim, vendo com mil olhos, será possível ver adequadamente e, a partir daquela "lei da perspectiva" que se lê no aforismo 162 de A gaia Ciência: "O egoísmo é a lei da perspectiva no âmbito do sentimento segundo o qual o que está próximo parece grande e pesado; e, à medida que se afastam, todas as coisas decrescem no tamanho e no peso". Ver com "mil olhos" e ver a partir do "pessoal" significa reconhecer tanto o perspectivismo quanto o egoísmo que marcam o novo

\footnotetext{
${ }^{3}$ Seguimos nesse texto a tradução proposta por Rubens Torres Filho (1991, p. 184) e Roberto Machado (1997, p. 45).
} 
modo de filosofar em sua tarefa de construir "os novos seres”. Para Nietzsche, o próprio ver já está ligado a um valorar e, nesse sentido, quem vê de mil formas, aprende a valorar de formas diferentes: "Egoísmo como ver e julgar perspectivísticos de todas as coisas [...]: todo ver (o fato de que em geral algo é percebido, este escolher) já é um valorar, um aceitar, em oposição a uma rejeição e a um não querer ver" (KSA 11, 26[71], p. 167). Quem vê, quando vê, valora. Quem vê de uma única forma, sempre a partir do lugar do outro (o altruísmo não é outra coisa do que ver - e avaliar segundo um diapasão alheio) nunca valora por si mesmo, mas sempre pelo outro.

Ora, Nietzsche esforça-se por demonstrar que todas as avaliações de valores são produtos de um ego, ou seja, de um determinado modo de ver, de determinados interesses e sentimentos que fundam visões diferentes de uma mesma coisa: "egoísmo enquanto um ver perspectivístico [perspektivische Sehen]" (KSA 11, 26[71], p. 167), é o modo de avaliação que rompe com a tradição gregária que faz ver apenas a partir de um ponto de vista, ou seja, que padroniza os comportamentos e escolhe um único modo de vida e de homem como sendo adequado do ponto de vista da comunidade. Se a grandeza está associada à multiplicidade de visões, a pequenez treme diante desse que é uma das condições para o crescimento das forças, o que a torna sempre mais débil:

Aos homens ordinários só lhes está permitido representar um rincão e uma esquina ínfima do caráter natural: perecem quando a multiplicidade dos elementos e a tensão dos contrários, ou seja, as precondições para a grandeza do homem, aumentam. (KSA 12, 10 [111]). 
Eis a crítica mordaz dirigida por Nietzsche à moralidade platônico-socrática-cristã em várias de suas obras: a moral que impõe um modo de ser como único possível é uma moral que impede o nascimento de "novos seres"; ainda mais porque esse único modo está amparado sobre os elementos negativos do desgosto do homem consigo mesmo e pela obrigação de dirigir-se constantemente ao outro, pela via do altruísmo e da compaixão. O além-do-homem, assim, nunca nascerá desse tipo de moral, na qual os homens estão condenados à repetição de si mesmos. Ao contrário, reconhecendo o papel do ego e a necessidade da estilização do caráter, a moral do futuro manteria abertos os olhos, vendo de mil formas e, assim, deixando aparecer o além-dohomem. É o que Nietzsche assumiu para si mesmo: "Transformação das avaliações - é minha tarefa" (KSA 9, 11 [76]). Transformar valores é abri-los para o processo de criação. Por isso, para Nietzsche, cabe à filosofia dar vazão à força criadora: "É vontade de vir-a-ser, crescer, dar forma, isto é, criar e, no criar, está incluído o destruir" (KSA 13, 17[13]). Criar é também destruir os valores antigos; há algo de violento em todo ato criador - e essas duas perspectivas estão reunidas na própria concepção do além-do-homem.

Assim, se a modernidade é o tempo associado por $\mathrm{Ni}$ etzsche aos valores da décadence, é nela que se situa a incapacidade para o olhar múltiplo que se desenha na perspectiva do além-do-homem. É o que se lê em Além de bem e mal:

Face a um mundo de 'ideias modernas', que gostariade confinar cada um num canto e numa 'especialidade', um filósofo, se hoje pudesse haver filósofos, seria obrigado a situar a grandeza,o conceito de 
'grandeza', precisamente em sua vastidão e multiplicidade, em sua inteireza, na multiplicidade: ele determinaria inclusive o valor e o grau, conforme quanto e quantas coisasum indivíduo pudesse aguentar e aceitar, conforme até ondepudesse estender sua responsabilidade. (...) [O] filósofo revelará algo deseu próprio ideal quando afirmar: '...precisamente a isto se chamará grandeza: poder ser tanto múltiplo como inteiro, tanto vasto como pleno.' (ABM, 212).

Em outras palavras, a filosofia também se revela como capacitada para a sua tarefa quando emite os valores (define o que é grandeza, por exemplo). Ao fazê-lo, está sinalizando para aquilo que reside em seu âmago, seja no sentido de que o filósofo seja um ser fraco e doente, seja um indivíduo pleno, capaz de corresponder à tarefa que lhe é devida.

\section{A DOUTRINA}

Assim falou Zaratustra seria, nesse sentido, a obra que traduz a tarefa central assumida por Nietzsche: "trabalhar sobre o homem, trabalhar para transformar o homem tal como existe na cultura contemporânea, quer dizer, ainda fazer nascer um novo tipo de homem" (WOTLING, 2016, p. 268). Isso já se verifica no Prólogo, onde já a primeira palavra dirigida aos homens do mercado é precisamente esta: "Eu vos ensino o além-do-homem. O homem é algo que deve ser superado. Que fizestes para superá-lo?” (ZA, Prólogo, 2). $\mathrm{O}$ ensinamento tem duas perspectivas: a primeira delas, retira o homem de seu lugar especial na história da vida, algo que o transformou em um fim em si mesmo, para o qual todas as coisas devem caminhar ("vós quereis ser a vazante dessa grande maré"); a segunda, explicita que a conquista dessa superação não é um produto do acaso, mas depende 
de um fazer, ou seja, de uma ação, apresenta-se propriamente como uma tarefa. Além disso, é possível identificar, como terceiro aspecto desse ensinamento, uma pista deixada por Nietzsche: "o além-do-homem é o sentido da terra. Que a vossa vontade diga: o além do homem é o sentido da terra" (ZA, Prólogo, 3). Esta afirmação e este convite passam pela noção de vontade: para cumprir a tarefa, é preciso desejar a superação, o que significa que o além-do-homem não é um estado de fato, mas um constante vir-a-ser ou vir-aconquistar. Se o primeiro aspecto é de ordem crítica (em relação ao passado do homem), os dois segundos são de ordem propositiva (em relação ao seu futuro). No meio estaria, precisamente, a tarefa da superação, do cultivo, da preparação e da criação desse novo tipo, o que passaria por uma fidelidade à terra ${ }^{4}$.

Nesse sentido o além-do-homem é um conceito orientado para o futuro, no sentido de que não se trata apenas de evocar a tarefa histórica ou mesmo genealógica das outras obras, mas de expressar com contundência, embora ainda de forma não totalmente elaborada e resolvida, o que cabe à filosofia e à moral. É precisamente nesse sentido que encontramos afirmação de Nietzsche: "sim, o homem foi o ensaio" (ZA, Da virtude dadivosa, 2). Porque é a mais plástica das criaturas e porque, afinal, "o que se pode amar no homem é que ele é uma transição” (ZA, Prólogo, 4), ele pode ser alterado por meio de condicionamentos e disciplinas variadas as quais podem tanto fortalecer as suas forças quan-

\footnotetext{
${ }^{4}$ Para uma análise dos usos e das aparições do termo Übermenschna filosofia de Nietzsche, ver: PASCHOAL, 2007; HAASE, 1984; ANSELL-PEARSON, 1982; BILATE, 2014; LOEB, 2005, entre outros.
} 
to, conforme ocorreu na tradição ocidental amplamente criticada por Nietzsche, adoecê-lo. Porque se deixou moldar no passado pelas outras moralidades, ele pode ser capaz de mudar-se novamente, pois não existe uma única versão do homem, mas várias. É dessa condição, por negar a ideia metafísica de uma essência ou natureza humana dada de uma vez por todas, que Nietzsche pode falar do além-do-homem. O homem afinal, "é o animal que não está ainda fixado de maneira estável", como se lê em Além de bem e mal, parágrafo 62 .

\section{A SUPERAÇÃO DO DESGOSTO}

O primeiro aspecto, de perspectiva crítica, diz respeito à superação do desgosto do homem em relação a si mesmo, produto do longo processo de adoecimento levado à cabo pela cultura e pela moral ocidental, traduzidas pelo esforço de domar a natureza e domesticar os instintos, levando ao esgotamento das forças vitais. $\mathrm{O}$ homem que deve ser superado é o homem do humanismo, o ser cativo da moralidade platônico-judaico-cristã, o animal de carga, abatido, a tal ponto que tem náusea si mesmo. Esse é o homem do passado, o homem da modernidade, o homem do humanismo, o produto da longa tarefa desempenhada pela cultura da décadence que orientou a história Ocidental. Essa perspectiva é central para a compreensão do além-do-homem para evitar que o conceito seja confundido com os processos de melhoramento implantados desde dentro dessa mesma cultura. Em Ecce Homo Nietzsche é muito claro a esse respeito: "Melhorar a humanidade? Eis a última coisa que eu prometeria. Não esperem de mim que eu erija novos ído- 
los!”(EH, Prólogo, 2).

O mesmo tom aparece em uma carta a sua amiga Malwida Von Meysenbug, datada de 20 de outubro de 1888, no qual ele afirma que todo "leitor sério deve saber que o tipo de homem que não inspira nojo é precisamente o tipo oposto dos ídolos ideais de outrora" (KSB, 1135). Ao afirmar assim, que é preciso ter cuidado com a interpretação do conceito, Nietzsche chama atenção para a "seriedade" com que ele deve ser lido, para evitar, precisamente, que o conceito seja associado à ideia de algum tipo de novo herói, salvador ou redentor. Isso significa que o além-do-homem não é um ideal, o que logo se depreende da exortação de fidelidade à terra: é essa fidelidade que garante ao além-dohomem um novo patamar que o distingue dos projetos tradicionais que, ao invés de superação, falam sempre de reforma e de melhoramento. Porque permanece fiel à terra, $\mathrm{o}$ além-do-homem não pode ser assumido como um novo ideal e, apenas assim, haveria realmente um futuro para o ser humano: "A mentira do ideal foi até agora a maldição que pesou sobre a realidade, a própria humanidade se tornou mentirosa e falsa até o mais fundo de seus instintos até a adoração dos valores opostos àqueles que poderiam lhe garantir um belo crescimento, um futuro" (EH, "Prólogo", 2). O Übermensch, nesse caso, é uma oposição ao "último homem" (ZA, Prólogo, 5).

\section{A CRIAC̣ÃO}

A recusa do peso que gera náusea no homem ocidental é o caminho portanto para grande libertação promovida pelo além-do-homem. Ao liberar o homem das amarras da dé- 
cadence, Nietzsche inventa o além-do-homem como um novo personagem, que se distinga e se eleve acima e para fora desses processos. Trata-se, por isso, de um ser de liberdade plena e, precisamente por isso, nem pode ser definido por inteiro, nem sequer pode emitir valores ou regras de orientação, porque o seu campo de atuação é o da plena criação, onde nada nunca está pronto. Tal como aquela criança do primeiro discurso do Zaratustra (ZA, das três metamorfoses), o além-do-homem não é apenas o criador da liberdade para a nova criação, mas é ele próprio o agente criador e o ato de criação. Só assim ele conquista o seu mundo pela via do jogo da criação que lhe é próprio. Com o além-do-homem o ser humano conquista novamente sua inocência. E é assim, como agente criador e, mais ainda, como ato criador, sua moral torna-se uma moral de futuro, cuja base é uma afirmação radical da vida terrena. Esse é o seu querer e ele deve ser considerado uma "modificação afetiva" da própria vontade humana, que, superado o desgosto, dirige-se à terra, como autoafirmação radical, como "sagrado dizer-Sim" pelo qual a humanidade poderia novamente "conquistar o seu mundo" (ZA, Das três metamorfoses).

Dessa forma, o além-do-homem está associado àquele "homem supremo", "que determina os valores e dirige a vontade de milênios pela direção que ele dá às naturezas mais elevadas" (KSA 11, 25[355]). Isso significa que a marca central do além-do-homem é precisamente a capacidade de criação de valores, o que significa que ele age segundo suas próprias concepções e afetos, os quais foram adensados em torno da ascensão das forças vitais. Ora, se a tradição gregária da filosofia pensara a virtude como o caminho para o 
bem, em Nietzsche a virtude é o caminho para a vida, ou seja, a condição de fortalecimento das forças vitais. Diante das virtudes e valores é preciso perguntar: "Obstruíram ou favoreceram até agora o prosperar da humanidade? São um signo de estado de indigência, de empobrecimento, de degeneração da vida? Ou, inversamente, denuncia-se neles a plenitude, a força, a vontade de vida, seu ânimo, sua confiança, seu futuro?" (GM, Prólogo).E é precisamente isso que o além-do-homem passa a simbolizar, ou seja, a capacidade de agir segundo a virtude que fortalece a vida. Ele é aquele que "torna novamente livre a vontade" e leva à superação do niilismo:

esse homem do futuro, que nos salvará não só do ideal vigente, como daquilo que dele forçosamente nasceria, do grande nojo, da vontade de nada, do niilismo, esse toque de sino do meio-dia e da grande decisão, que torna novamente livre a vontade, que devolve à Terra sua finalidade e ao homem sua esperança, esse anticristo e anti-niilista, esse vencedor de Deus e do nada - ele tem de vir um dia...”. (GM II, 24)

Essa perspectiva futura de uma nova esperança coaduna-se com o caminho ascendente inaugurado pela própria filosofia de Nietzsche em direção a uma superação da velha cultura em direção um novo tipo de ser: "ninguém antes de mim conhecia o caminho reto, o caminho para cima: apenas a partir de mim há novamente esperanças, tarefas, caminhos a traçar para a cultura -" (EH, Crepúsculo dos idolos, 2). Esse caminho, contudo, depende da filosofia, que deve assumir a sua tarefa de parir mesmo aquilo que parece mais absurdo e mais estranho, como é o caso do além-dohomem. No Prólogo à Gaia Ciência, Nietzsche escreve:

Um filósofo que passou pormuitas saúdes, e que sempre passa de 
novo por elas, também atravessou outras tantas filosofias: nempode ele fazer de outro modo, senão transpor cada vez seu estado para a forma e distância maisespirituais - essa arte de transfiguração é justamente filosofia. [...] Não somos rãs pensantes, nem aparelhos de objetivação e máquinas registradoras com vísceras congeladas - temos constantementede parir nossos pensamentos de nossa dor e maternalmente transmitir-lhes tudo o que temos em nós de sangue, coração, fogo, prazer, paixão, tormento, consciência, destino, fatalidade." (GC, Prólogo, 3).

Como uma tarefa de criação, à filosofia cabe parir o pensamento a partir da vida em tudo o que isso significa, tanto os aspectos agradáveis e positivos, quanto os negativos e indesejáveis. $O$ filósofo experimenta isso quando reconhece que o pensamento é sintoma do seu corpo e é nele que se produzem as ideias: quanto mais rico experimentado (inclusive nas doenças e dores) é um corpo (um filósofo), mais ele poderá expressar essa perspectiva criadora e criativa que o prepara para a tarefa da criação e do cultivo do além-do-homem. É preciso, nesse caso, muita energia e vigor criativo para que uma tal perspectiva torne-se possível.É isso que Nietzsche parece ter desejado e praticado como filosofia.

\section{CONSIDERAÇÕES FINAIS}

Como já dissemos, embora Nietzsche reconheça o nascimento fortuito desse tipo de homem no passado, quebrando com a lógica do progresso evolutivo que caracteriza o modo tradicional de pensamento, ele também reconhece que esse aparecimento foi fruto de um mero acaso. Dessa forma, ao expressar o além-do-homem como algo a ser desejado, ele também expressa a ideia de que é preciso prepará- 
lo: eis a missão da moralidade, da cultura, da educação e da arte, que devem obter e desenvolver as condições capazes de elevar o homem. Em outras palavras, como todo tipo de homem é definido pelo modo como ele lida pela suas posições ou, melhor, por quais pulsõese afetos lhe predominantes, então é pela modificação do sistema pulsional do homem que se fomentam determinamostipos, inclusive o próprio além-do-homem. Nesse caso, o esforço, a disciplina, o domínio, o controle e o poder devem ser dirigidos e orientados para a nova tarefa assumida pela filosofia. Em outras palavras, para que haja essa educação dos afetos, Nietzsche reconhece a necessidade de um processo que comece pela imposição de restrições, passe pela prática de hábitos, pela atenção a necessidades e pelo domínio da inclinação natural (ou seja, das pulsões e afetos). Dado que os valores nascem dos afetos, então a verdadeira filosofia, aquela precisamente que se pergunta sobre os valores, deve constituir-se como uma tarefa de criação, já que esse é o modo mais eficaz (e talvez mesmo o único possível) de intervir na ação de um homem. A esse processo Nietzsche chama de incorporação: é preciso que os valores sejam incorporados.

Dessa forma, se a moral vigente foi sempre uma moral "contrária aos sentidos, aos instintos, à natureza, ao animal, em suma, [a]os ideais ate agora vigentes, todos ideais hostis à vida, difamadores do mundo" (GM, II, 24), então, por isso, a moral do futuro, representada pelo além-do-homem deve ser entendida como uma preparação e um cultivo das forças vitais em vista de uma intervenção no âmbito dos afetos e pulsões que moldam o caráter de um indivíduo. Nietzsche, assim, contrapõe-se mais uma vez à tradição 
logocêntrica da tradição ocidental, que valorizou o cultivo do intelecto como expressão máxima do melhoramento humano, em nome do reconhecimento do homem como um campo de relações de domínio cujas operações (afetivas, volitivas e racionais) ocorrem no corpo, como lugar da dinâmica do poder.

Para finalizar, podemos mencionar o problema da temporalidade, ou melhor ainda, o paradoxo da temporalidade: quando chegará o tempo do Übermensch?A pergunta fica sem resposta e, no limite, sem sentido quando reconhecemos que o além-do-homem está entre dois tempos possíveis: ele não é nenhum agora mas também não é umjamais. Ao contrário, como tarefa, ele é "alguma coisa pela qual se vale a pena viver na Terra" (ABM, 188); porque, afinal, assumido como ocupação filosófica, ele permanece como uma esperança: "esse homem do futuro", "ele tem de vir um dia...” (GM II, 24). Afinal, como filósofo, Nietzsche afirma: "eu não sou um buscador. Quero criar para mim meu próprio sol” (GC 320). Talvez devêssemos pensar no além-do-homem como um enigma, duvidoso o suficiente como se fôssemos Édipo diante de sua Esfinge.

Abstract: In this article, we intend to analyze the concept of Overman in Nietzsche from the idea of Züchtung, understanding this as a task assumed by Nietzschean philosophy itself and bequeathed as a mission for all philosophy. In this sense, it begins with an analysis of the concept of Züchtung in Nietzsche's work, articulating it with the conditions proper for the cultivation and creation of Übermensch and the effectiveness of its doctrine. Thereafter, it will be assessed how the creation of such conditions requires overcoming disgust to guarantee the possibility of creating the Overman.

Keywords: Züchtung; Overman; Übermensch; philosophical task; doctrine. 


\section{REFERÊNCIAS}

ANSELL-PEARSON, Keith. Who is the Ubermensch? Time, truth, and woman in Nietzsche. Journal of the History of Ideas, p. 309-331, 1992.

BILATE, Danilo. Nietzsche, entre o Übermensch e o Unmensch. Cadernos Nietzsche, v. 1, n. 34, p. 215-229, 2014.

HAASE, Marie-Louise. "Der Übermensch in Also Sprach Zarathustra und im Zarathustras-Nachlass 1882-1885". Nietzsche-Studien, v.13, 1984.

LOEB, Paul S. Finding the Übermensch in Nietzsche's Genealogy of Morality. Journal of Nietzsche Studies, p. 70-101, 2005.

MACHADO, Roberto. Zaratustra, Tragédia Nietzschiana. Rio de Janeiro: Jorge Zahar Editor, 1997, p. 45.

NIETZSCHE, $\mathrm{F}$.

SämtlicheWerke.

KritischeStudienausgabe (KSA). Herausgegeben von Giorgio ColliundMazzinoMontinari. Berlin: Walter de Gruyter \& Co, 1988.

- A gaia ciência. Trad. Paulo César de Souza. São Paulo: Companhia das Letras, 2012.

Além do bem e mal: prelúdio a uma filosofia do futuro. Tradução de Paulo César de Souza. São Paulo: Companhia das Letras, 2005.

. Assim falou Zaratustra: um livro para todos e para ninguém. Tradução, notas e posfácio Paulo César de Souza. São Paulo: Companhia das Letras, 2011. 
. Ecce homo: como alguém se torna o que é. Tradução de Paulo César de Souza. São Paulo: Companhia das Letras, 1995.

. Humano, demasiado humano: um livro para espíritos livres. Tradução de Paulo César de Souza. São Paulo: Companhia das Letras, 2000.

. Humano, demasiado humano: um livro para espíritos livres volume II. Tradução de Paulo César de Souza. São Paulo: Companhia das Letras, 2008.

. Obras incompletas. 5. ed. São Paulo: Nova Cultural, 1991, vol. II.

PASCHOAL, Antonio Edmilson. A palavra Übermensch nos escritos de Nietzsche. Cadernos Nietzsche, n. 23, p. 105-121, 2007.

WOTLING, Patrick. Oui, l'hommefut un essai: Philosophie de l'avenirselon Nietzsche. Paris: Presses Universitaires France, 2016. 